Running head: SELF-MANAGEMENT OF HEALTH

Self-Management of Health by People with Intellectual and Developmental Disabilities

Carli Friedman, Mary C. Rizzolo, \& Natasha A. Spassiani

Corresponding author:

Carli Friedman, PhD

Email: cfriedman@thecouncil.org

CQL | The Council on Quality and Leadership

100 West Road, Suite 300

Towson, MD, 21204, USA

Mary C. Rizzolo, PhD

CQL | The Council on Quality and Leadership

Natasha A. Spassiani, PhD

Edinburgh Napier University 


\begin{abstract}
Background. Self-management of health includes people with intellectual and developmental disabilities (IDD) playing a key role in health management in collaborating with health care professionals.
\end{abstract}

Methods. This study analyzed data from Personal Outcome Measures ${ }^{\circledR}$ surveys $(n=1,341)$ to explore self-management of health. We had the following research questions: who is most likely to be supported to self-manage their health?; how does being supported to self-manage impact different areas of health?; and, how does being supported to self-manage impact other healthrelated organizational supports?

Results. Findings revealed the impact of self-management of health can be wide-ranging, regardless of impairment severity. When supported to self-manage their health, health care professionals were more likely to address health care issues, and interventions were more likely to be effective.

Conclusions. Self-management represents a paradigm shift for people with IDD because it transforms people from passive recipients to active directors of their health.

Keywords: Self-management of health, organizational supports, people with intellectual and developmental disabilities, participant direction 


\section{Self-Management of Health by People with Intellectual and Developmental Disabilities}

Compared with the general population, people with intellectual and developmental disabilities (IDD) have significantly poorer health and shorter life expectancies (Ouellette-Kuntz, 2005; Taggart \& Cousins, 2014). For example, a recently systematic review found people with IDD are more likely to die 20 years younger than nondisabled people, due largely to preventable causes (O'Leary, Cooper, \& Hughes-McCormack, 2017). People with IDD's higher rates of chronic health conditions are due to environmental conditions, genetics, social circumstances, and issues with access to health care services (Bittles et al., 2002; Krahn, Hammond, \& Turner, 2006; Ouellette-Kuntz, 2005; Taggart \& Cousins, 2014). Prevalence of cardiovascular disease, obesity, hypertension, osteoporosis, and poor oral health are all higher among people with IDD compared to nondisabled people (Centers for Disease Control and Prevention, 2017). Moreover, many people with IDD experience age-related health conditions earlier than the general population, and at an increased rate (Glasson, Dye, \& Bittles, 2014; World Health Organization, 2001). Those people with IDD who do not receive support services also have higher smoking rates, and are less likely to visit the dentist or have their vision or hearing tested (Emerson, 2011). These health disparities are all exacerbated by poverty and social exclusion, which are key social determinants of health (Ouellette-Kuntz, 2005).

Research indicates health and quality of life are connected to community integration and social inclusion for people with IDD (Heller, McCubbin, Drum, \& Peterson, 2011; Marks, Sisirak, \& Heller, 2010). Yet, even living in the community, people with IDD have higher risks of adverse health conditions, such as type II diabetes, earlier in life compared to the general population (Ouellette-Kuntz, 2005; Rimmer \& Yamaki, 2006; Yamaki, 2005). Moreover, the 
increased risk of these health conditions may negatively impact people with IDD's ability to engage in the community.

In the United States, Medicaid is the public health insurance program for low income people, including many people with disabilities. Medicaid is the single largest source of public health coverage in the United States, covering approximately 70 million Americans (Paradise, 2015). Medicaid is also the largest provider of long term services and supports (LTSS) for people with IDD (Braddock, Hemp, Tanis, Wu, \& Haffer, 2017).

Originally, Medicaid funding for people with IDD was available when the person was placed in an institutional setting, with few options for supporting individuals in their homes and/or communities. In 1981, the United States authorized the Medicaid Home and Community Based Services (HCBS) waiver program as an alternative to institutionalized funding. The HCBS waiver program allow states to provide more flexible LTSS in the community that is targeted to underserved populations, such as people with IDD. The HCBS waiver program has grown exponentially to become the largest provider of LTSS for people with IDD because of the benefits of community living, the preferences of people with IDD, and the cost-effectiveness of community living compared to institutions (Braddock et al., 2017; Hemp, Braddock, \& King, 2014; Lakin, Larson, \& Kim, 2011). In fiscal year 2015, \$25.6 billion in federal funds were projected for HCBS waiver services for 630,000 people with IDD (Friedman, 2017).

Despite the introduction of a public community-based funding model (HCBS waivers), "the legacy of institutionalization and congregate care has shaped current residential services [for people with IDD], meaning that 'services today have become standardized, inflexible and unaccountable to those they serve"” (Spagnuolo, 2016, n.p.). As such, and because it "promotes personal choice and control over the delivery" of services (Disabled and Elderly Health 
Programs Group et al., 2015, p. 193), the United States Centers for Medicare and Medicaid Service (CMS) has "urged all states to afford [HCBS] waiver participants the opportunity to direct some or all of their waiver services, without regard to their support needs" (Medicaid Program, 2014, n.p.).

Self-management of services, also referred to as participant or consumer direction, has grown exponentially for people with IDD in the United States because of its ability to result in fewer unmet needs, increased physical and emotional well-being for people with IDD, and increased control (Heller, Arnold, McBride, \& Factor, 2012; Swaine, Parish, Igdalsky, \& Powell, 2016; Timberlake, Leutz, Warfield, \& Chiri, 2014). Not only does self-management allow people with IDD to direct their services and supports, it also leads to increased satisfaction, choice, empowerment, and quality of life (Heller et al., 2012; Swaine et al., 2016; Timberlake et al., 2014).

Self-management of health in particular refers to "people [with IDD being] involved in their own healthcare, including decisions about healthcare providers and the services they receive... all people [with IDD should be] afforded the same choices in healthcare available to others [without disabilities]" (The Council on Quality and Leadership, 2015, p. 24). In order to self-manage their health the person has to be supported to understand know how their impairments or diagnoses impact them (e.g., seizure disorder signs and symptoms), and what health treatment options that are available, and be involved in the decision making regarding treatments; without education about these things, choice is not truly choice. It also means not keeping information about health (e.g., cancer) from the person with IDD because of the potential fears associated. The person also has to be able to see the specialists they want to see. 
The person also has to be able to refuse treatment, as long as they understand the risks and benefits of taking or refusing treatment.

Self-management of health at its core is about people with IDD having control over their health at both a small scale (e.g., making their own appointments), and a large scale (e.g., treatment decisions). The scope of self-management is person centered - it depends on the extent to which the person would like to self-manage their health. Moreover, just because a person needs supports to participate in some aspects of self-management, does not mean they are not capable in participating in self-management. Having support or assistance does not mean people with IDD are not self-determined or capable (Caldwell, 2011). The majority, if not all, nondisabled people consult with others about their medical decisions, people with IDD should be able to be similarly interdependent without being deemed incapable.

Currently, in the United States, disability service organizations tend to do things for people when it comes to healthcare, instead of helping the person to do them, because of agency liability - they over support because of risk. Organizations are likely worried about increased liability if the person ignores doctors' orders. There is a "perceived trade-off between autonomy and safety" (Heller et al., 2012, p. 77). Fears about the downsides of self-management include people with IDD not following doctor's orders or missing needed appointments or laboratory testing. While these may result in people getting sicker, that is a risk all people face, nondisabled or with IDD. The best support involves balancing duty of care and dignity of risk. Avoidance of risk is often built into the built and social environments of people with IDD (Perske, 1972). However, "it is difficult to learn how to make decisions and handle risk if the chance to undertake either of these activities is denied... [parents and providers are] keen to encourage decision-making in theory but unwilling to allow choices that result in very minimal risky 
behavior" (Hudson, 2003, p. 261). It is the organization's responsibility to support the person to understand the risks and benefits to reduce this risk, rather than take away their choices altogether.

Because of the benefits of self-management of services, especially in regard to giving people with IDD more control over their lives, the aim of this study was to explore the selfmanagement of health by people with IDD, including how self-management can improve health. We had the following research questions: who is most likely to be supported to self-manage their health?; how does being supported to self-manage impact different areas of health?; and, how does being supported to self-manage impact other health-related organizational supports? To answer these questions, this study analyzed secondary data from Personal Outcome Measures ${ }^{\circledR}$ surveys from approximately 1,300 people with IDD.

\section{Methods}

\section{Participants}

As this analysis was of secondary data, institutional review board determined it was exempt from review. Participants were originally recruited to participate over approximately two years (January 2015 - December 2016) through organizations in the United States that provide services to people with disabilities, including: service coordination; case management; family and individual supports; behavioral health care; employment and other work services; residential services; non-traditional supports (micro-boards and co-ops); and, human services systems. 1,341 people with IDD consented to participate in this study. Participant demographics are presented in Table 1.

\section{Measure}

The instrument used in this study was the Personal Outcome Measures ${ }^{\circledR}$ 
(The Council on Quality and Leadership, 2017a), developed by the international non-profit disability organization The Council on Quality and Leadership (CQL). The Personal Outcome Measures ${ }^{\circledR}$ tool is designed to determine people with disabilities' quality of life, including selfdetermination, choice, self-advocacy, and supports. The Personal Outcome Measures ${ }^{\circledR}$ includes 21 indicators divided into five factors: my human security; my community; my relationships; my choices; and, my goals. My human security includes indicator people have the best possible health, which was utilized in this study.

Personal Outcome Measures ${ }^{\circledR}$ administration occurs in three stages. In the first stage, a trained Personal Outcome Measures ${ }^{\circledR}$ interviewer has in-depth conversations with the participant with disabilities about each of the indicators following specific open-ended prompts. During the second stage of the Personal Outcome Measures ${ }^{\circledR}$ interview, the interviewer speaks with someone who knows the participant with disabilities and their organizational supports, such as a direct support professional, and asks them questions about individualized supports and outcomes to fill in any gaps. During the final stage, the interviewer observes the participant in various settings, and then completes the indicator questions about personal outcomes and individualized supports based on the information gathered in the three stages. Individual record reviews are also conducted as needed.

The Personal Outcome Measures ${ }^{\circledR}$ was developed over 25 years ago based on findings from focus groups with people with disabilities, their family members, and other key stakeholders about what really mattered in their lives. The Personal Outcome Measures ${ }^{\circledR}$ has been continuously refined over the past two decades through pilot testing, 25 years of administration, commission of research and content experts, a Delphi survey, and feedback from advisory groups (The Council on Quality and Leadership, 2017a). The Personal Outcome 
Measures ${ }^{\circledR}$ has inter-rater reliability and construct validity (Friedman, 2018; The Council on Quality and Leadership, 2017b).

\section{Variables and Analysis}

Following the above procedure, suggested questions for information gathering with the participant for about health included:

- "Do you feel healthy? If no, what bothers you?

- What do you do to stay healthy?

- What health concerns (physical and mental) do you have?

- Do you discuss your health concerns with anyone? How are your questions or concerns addressed?

- Are you seeing a doctor, dentist, and other health care professionals?

- Do you receive regular exams? What kind?

- Do you take any medication? If so, what is it and how does it help?

- What advice has your health care professional given you? Are you following it? If yes, is it working? If no, what do you think the problem is?

- If you think the medications, treatments, or interventions are not working, what is being done?” (The Council on Quality and Leadership, 2017a, p. 22)

The interviewer was provided the following suggested question to utilize during the interview with the participant with IDD's staff regarding health:

- "How has the person defined best possible health?

- What preventive health care measures are in place for the person?

- How is the person involved in his or her own health care? 
- Is the person following the health care professional's recommendations? If no, why do you think that is?

- Do you think the person feels health interventions are working?

- If not, what is being done about it?

- How have you explored health issues with the person?

- What supports does the person need to achieve or maintain best possible health?

- Who provides the support?

- How was this decided?

- How do you assist the person to overcome barriers to this outcome?

- What organizational practices, values, and activities support this outcome for the person?" (The Council on Quality and Leadership, 2017a, p. 22)

Utilizing the information gathered from these interviews, as well as record reviews and observations as needed, the interviewer then completes the probes about the person's health outcomes and supports, including self-management of health.

\section{Analysis}

To explore self-management of health we first wanted to examine who was most likely to be supported to self-manage their health. To do so, demographics variables were run in binary logistic regression models as the independent variables (IVs) with the question "is the participant supported to self-manage their health" as the dependent variable (DV). (It should be noted a number of races/ethnicities (e.g., Asian, other Pacific Islander, Native Hawaiian, other) were combined into an 'other' category because of low frequencies of each of the groups). Then, in order to explore how self-management of health impacts both ones' health and organizational supports, binary logistic regression models were run with self-management of health as the IV in 
each of the models with different health outcomes or organizational supports in place as DVs

(Table 2); daily support needs were also controlled as a proxy for severity of impairment.

Bonferroni correction was used to account for running multiple models (.008 and .01

respectively). With all of the models, when they were significant, univariate analyses were run to determine odds ratios.

\section{Results}

Although the overwhelming majority of the participants in our study had effective health services, and most received supports regarding health services, only slightly more than half of the participants in our study were supported to self-manage their personal health.

\section{Likelihood to Self-Manage Health}

A binary logistic regression model was performed with the DV self-management of health and the demographic IVs to determine who was most/least likely to self-manage their health; the model was significant, $-2 L L=1167.99, \chi^{2}(48)=205.71, p<.005$. The model, which correctly classified $69.5 \%$ of cases, explained $25.0 \%$ (Nagelkerke $R^{2}$ ) of variance. Table 3 details odds ratios. According to univariate statistics the people ages 65 to 74 , and 75 and older were 2.90 and 3.47 times more likely than people aged 18 to 24 to self-manage their health, respectively. White people were 1.56 times more likely to be supported to self-manage their health than Black or African American People, and 12.50 times more likely than people in the other race/ethnicity category; conversely, American Indian or Indigenous Alaskan people were 2.64 times more likely than White people to be supported to self-manage their health.

People with complex medical needs were 1.78 times more likely to be supported to selfmanage their health than people without these needs. Moreover, people with behavior challenges were 1.64 times more likely to be supported to self-manage their health than people not in this 
disability category. Whereas, people with personality/psychotic disorder were 1.79 times less likely than people without this disability.

People with independent decision making were 3.57 times and 1.75 times more likely to be supported to self-manage their health than people with assisted decision making or full/plenary guardianship respectively. Those people with disabilities that lived in family homes were 1.89 times less likely to be supported to self-manage compared to people who live in their own homes/apartments. People with the highest support needs (twenty-four/seven around the clock daily support) were 4.00 times less likely to self-manage their health than people with support as needed (on call). Finally, people who received services from a managed care organization were 1.92 times less likely to be supported to self-manage their health than people not being served by a managed care organization. The following variables were not significant: gender; primary communication method; all other disability types other than those mentioned; and, complex behavioral health needs (see Table 3).

\section{Impact of Self-Management on Different Areas of Health}

When binary logistic regression models were run to determine the impact of selfmanagement of health (IV) on different areas of ones' health (DVs), controlling for daily support, it was determined that people who were supported to self-manage their health were not significantly more or less likely to see health care professionals, have primary care doctors, or have devices or equipment (e.g., glasses, hearing aids, dentures) available and in good repair than people not supported to self-manage their health (Table 4). However, those who were supported to self-manage their health were 2.81 times more likely to have health care professionals identify their best possible health situation, including addressing their health care issues, concerns, and/or interventions. Compared to people not supported to self-manage their 
health, whose who did were 7.37 times more likely to select their health intervention services in consultation with their health care professional. Moreover, people supported to self-manage their health were 2.30 times more likely to have effective health intervention services compared to those not supported to self-manage their health.

\section{Impact on the Organizational Supports One Receives}

Binary logistic regression models were also run to determine the impact of selfmanagement of health (IV) on different individualized organizational supports (DVs), controlling for daily support needs; each of the models was statistically significant (see Table 4). Findings revealed when people were supported to self-manage their health, the organization supporting them was 9.03 times more likely to know their definition of best possible health. When people were supported to self-manage their health, organizations were 4.10 times more likely to support them to promote and maintain best possible health. Compared to people not supported to self-manage their health, those who did were 5.12 more likely to have organizations support them to obtain regular medical and health services. When people were supported to selfmanage their health, organizations were 6.23 more likely to respond to people's changing health needs and preferences. Moreover, people self-managed their health were 22.42 times more likely to have organizations support them to be aware of their medical issues and their impact than people who did not self-manage their health.

\section{Discussion}

Self-management of services not only increases choice and empowerment, it can also produces better outcomes (Heller et al., 2012). For this reason, the aim of this study was to explore if and how people with IDD are supported to self-manage their health. Personal Outcome Measures ${ }^{\circledR}$ interviews from approximately 1,300 people with IDD were utilized to determine 
who was most likely to be supported to self-manage their health as well as the benefits of selfmanagement on different areas of health and the types of organizational supports one receives.

Our findings revealed the impact of self-management of health can be wide-ranging there are a number of significant benefits regardless of impairment severity. When people with IDD were supported to self-manage their health, health care professionals were more likely to identify the person's best possible health situation and address any health care issues or concerns, and health intervention services were more likely to be selected by the person in consultation with health care professionals. Health intervention services were even more likely to be effective. Although the relationship is likely bidirectional, the type of active advocacy that comes with self-management of health is related to increases in the odds organizations will provide supports to promote and maintain best possible health, respond to the person's changing health needs and preferences, know the person's definition of best possible health, and support the person to be aware of their medical issues and their impact.

While participant centered care should be the gold standard and goal for all healthcare interactions, in no way should the quality or effectiveness of ones' health care depend on selfmanagement. According to the Office of the United Nations High Commissioner for Human Rights and World Health Organization (2008) "the right to health is a fundamental part of our human rights and of our understanding of a life in dignity" (p. 5). People with IDD already face an increased number of health disparities compared to both nondisabled people and people with other disabilities (Ouellette-Kuntz, 2005; Taggart \& Cousins, 2014), indicating a need for a strengthening of services and supports for people with IDD. People with IDD have also noted disrespect from health care professionals, in terms of professionals directing conversations or questions to their staff or family, or disrespecting their decisions (Ervin, Hennen, Merrick, \& 
Morad, 2014; Friedman, Arnold, Owen, \& Sandman, 2014). Thus, while there should be an expansion of opportunities for self-management of health for people with IDD, for these health disparities to be reduced, there also needs to be an influx in respect, and negative assumptions and stereotypes about people with IDD also need to dismantled. All people are entitled to quality health care (UN General Assembly, 1948).

As such, there are also a number of disparities in self-management of health opportunities for people with IDD that require attention. There were some groups that were more likely to be supported to self-manage their health, such as older adults, people with behavioral challenges, and people with complex medical needs, that should be research further to examine if these findings were sample specific or due to confounding variables. Our study also revealed a number of variables that resulted in lower odds for self-management. For example, people with personality/psychotic disorder were less likely to be supported to self-manage their health. People with assisted decision making and full/plenary guardianships were less likely to be supported to self-manage their health than people with independent decision making. In its essence guardianship in the United States includes rights limitations where others are making critical legal and health decisions on ones' behalf. However, there is no reason that people with guardianship cannot be supported to play an active role in their health. In fact, Salzman (2011) argues the current United States sweeping guardianship system violates the Americans with Disabilities Act (1990) and Supreme Court decision Olmstead v. L.C. (1999) because it does not limit decision making rights in the least restrictive manner. There has been a movement across the world, and more recently in the United States, to shift to supported decision making, a leastrestrictive guardianship model which avoids automatically giving guardians broad sweeping powers by creating assisted opportunities for people with disabilities to exercise legal capacity 
(Salzman, 2011). While people with high support needs were less likely to self-manage their health, the benefits of self-management were significant even when controlling for daily support needs indicating there are benefits for all people to play an active role in their health, regardless of severity of impairment or legal capacity.

Our findings also revealed significant racial/ethnic disparities in terms of who is supported to self-manage their health. Black people, Asian people, Pacific Islanders, Native Hawaiians, and people of 'other' ethnicities all had lower odds of being supported to selfmanage their health than White people. While there may have been interactions or other confounding variables that were not included in the analyses, it is also possible these findings are related to racial biases. Research has documented both the existence of racial and ethnic health disparities for people of color, and how racial prejudices can negatively impact the healthcare that people of color receive (Magaña, Parish, Morales, Li, \& Fujiura, 2016; Murphy-Berman, Berman, \& Campbell, 1998; Nelson, Stith, \& Smedley, 2002). More research is needed to determine why there were racial/ethnic differences, specifically in terms of self-management of health opportunities for people with IDD, in order to provide equal opportunities.

According to our findings, people who receive support from a managed care organization were also less likely to be supported to self-manage their health than those not receiving managed care. As states are grappling with a reduced fiscal landscape, many states have moved towards managed care - privatization of Medicaid service provision. Medicaid managed care "provides for the delivery of Medicaid health benefits and additional services through contracted arrangements between state Medicaid agencies and managed care organizations (MCOs) that accept a set per member per month (capitation) payment for these services" (Centers for Medicare and Medicaid, n.d.). The aim of Medicaid managed care is to reduce program costs and 
provide better utilization of health services through the contracting of MCOs. As of July 2014, 55 million people in the United States were enrolled in Managed (Centers for Medicare and Medicaid, n.d.). Yet, there is conflicting research about the benefits of managed care for people with disabilities in the United States, particularly the cost effectiveness and quality (Burns, 2009; Caswell \& Long, 2015; Duggan \& Hayford, 2013; Wegman et al., 2015; Williamson et al., 2017).

Indeed, participants in our study who had managed care were less likely to have opportunities to self-manage their own health care, compared to those not on managed care. The relationship between managed care and self-management of health is an important topic for future study; this is especially pertinent as this service delivery model is relatively new for people with IDD, yet is rapidly growing in frequency in the United States (Williamson et al., 2017). People with IDD are a unique population that, in many instances, require a different set of services and supports than nondisabled people or even people with other types of disabilities. Evidenced-based standards and guidelines about managed care provision for people with IDD is more critical than ever.

\section{Limitations}

When interpreting our results, a number of limitations should be noted. Our data was not representative of people with IDD in the United States as a whole. While 22 states were represented in the sample, three states were most frequently represented. Most of our participants were also White. Additionally, participants were recruited through organizations that provide LTSS, particularly those organizations who partner with CQL to conduct Personal Outcome Measures ${ }^{\circledR}$ interviews; therefore, this sample may not be representative of all people with IDD, or all service providers. When interpreting our results, it should also be noted that Personal 
Outcome Measures ${ }^{\circledR}$ variables may be correlated, impacting the study's findings. Finally, it should be noted that as this was secondary data, the authors did not have the ability to ask additional questions or create new variables.

\section{Conclusion}

Self-management of their health includes the person with disabilities playing a key role in health management, and collaboration with health care professionals (Lorig, Sobel, Ritter, Laurent, \& Hobbs, 2001). Self-management can lead to improvements in health behaviors, selfefficacy, and health status (Lorig et al., 2001; Ory, Ahn, Jiang, Lorig, et al., 2013; Ory, Ahn, Jiang, Smith, et al., 2013). The engagement aspect of self-management of health can also lead to more efficient health care delivery (Panagioti et al., 2014). Self-management of health represents a paradigm shift for people with IDD because it transforms them from passive recipients to active directors of their own health. 


\section{References}

Americans With Disabilities Act of 1990, Pub. L. No. 101-336, 104 Stat. 328, (1990).

Bittles, A. H., Petterson, B. A., Sullivan, S. G., Hussain, R., Glasson, E. J., \& Montgomery, P. D. (2002). The influence of intellectual disability on life expectancy. The Journals of Gerontology Series A: Biological Sciences and Medical Sciences, 57(7), M470-M472. doi:10.1093/gerona/57.7.M470

Braddock, D., Hemp, R., Tanis, E. S., Wu, J., \& Haffer, L. (2017). The state of the states in intellectual and developmental disabilities: 2017 (11th ed.). Washington, DC: The American Association on Intellectual and Developmental Disabilities.

Burns, M. E. (2009). Medicaid managed care and health care access for adult beneficiaries with disabilities. Health services research, 44(5p1), 1521-1541.

Caldwell, J. (2011). Disability identity of leaders in the self-advocacy movement. Intellectual and Developmental Disabilities, 49(5), 315-326.

Caswell, K. J., \& Long, S. K. (2015). The expanding role of managed care in the Medicaid program: Implications for health care access, use, and expenditures for nonelderly adults. INQUIRY: The Journal of Health Care Organization, Provision, and Financing, 52, 117.

Centers for Disease Control and Prevention. (2017). Disability and obesity. Retrieved from https://www.cdc.gov/ncbddd/disabilityandhealth/obesity.html

Centers for Medicare and Medicaid. (n.d.). Managed Care. Retrieved from https://www.medicaid.gov/medicaid/managed-care/index.html

Disabled and Elderly Health Programs Group, Center for Medicaid and State Operations, Centers for Medicare and Medicaid Services, \& Department of Health and Human Services. 
(2015). Application for a §1915(c) Home and Community-Based Waiver [Version 3.5]:

Instructions, technical guide, and review criteria. Retrieved from

http://www.medicaid.gov/Medicaid-CHIP-Program-Information/By-

\section{Topics/Waivers/Downloads/Technical-Guidance.pdf}

Duggan, M., \& Hayford, T. (2013). Has the shift to managed care reduced Medicaid expenditures? Evidence from state and local-level mandates. Journal of Policy Analysis and Management, 32(3), 505-535.

Emerson, E. (2011). Health status and health risks of the "hidden majority" of adults with intellectual disability. Intellectual and Developmental Disabilities, 49(3), 155-165.

Ervin, D. A., Hennen, B., Merrick, J., \& Morad, M. (2014). Healthcare for persons with intellectual and developmental disability in the community. Frontiers in public health, 2(83), 1-8. doi:10.3389/fpubh.2014.00083

Friedman, C. (2017). A national analysis of Medicaid Home and Community Based Services waivers for people with intellectual and developmental disabilities: FY 2015. Intellectual and Developmental Disabilities, 55(5), 281-302. doi:10.1352/1934-9556-55.5.281

Friedman, C. (2018). The Personal Outcome Measures ${ }^{\circledR}$. Disability and health journal, 11(3), 351-358. doi:10.1016/j.dhjo.2017.12.003

Friedman, C., Arnold, C. K., Owen, A. L., \& Sandman, L. (2014). "Remember our voices are our tools:" Sexual self-advocacy as defined by people with intellectual and developmental disabilities. Sexuality \& Disability, 32(4), 515-532. doi:10.1007/s11195-014-9377-1

Garson, G. D. (2008). Path analysis. from Statnotes: Topics in Multivariate Analysis. Retrieved, $9(05), 2009$. 
Glasson, E., Dye, D., \& Bittles, A. H. (2014). The triple challenges associated with age-related comorbidities in Down syndrome. Journal of Intellectual Disability Research, 58(4), 393-398. doi:10.1111/jir.12026

Heller, T., Arnold, K., McBride, E., \& Factor, A. (2012). Consumer-directed support: Impact of hiring practices on adults with I/DD and families. International Journal of Integrated Care, 12(9), 76-87.

Heller, T., McCubbin, J. A., Drum, C., \& Peterson, J. (2011). Physical activity and nutrition health promotion interventions: What is working for people with intellectual disabilities? Intellectual and Developmental Disabilities, 49(1), 26-36. doi:10.1352/1934-955649.1 .26

Hemp, R., Braddock, D., \& King, M. (2014). Community-based Medicaid funding for people with intellectual and development disabilities. NCSL legisbrief, 22(7), 1.

Hudson, B. (2003). From adolescence to young adulthood: The partnership challenge for learning disability services in England. Disability \& Society, 18(3), 259-276. doi:10.1080/0968759032000052851

Krahn, G. L., Hammond, L., \& Turner, A. (2006). A cascade of disparities: Health and health care access for people with intellectual disabilities. Mental Retardation and Developmental Disabilities Research Review, 12, 70-82.

Lakin, K., Larson, S., \& Kim, S. (2011). Behavioral outcomes of deinstitutionalization for people with intellectual and/or developmental disabilities: Third decennial review of US studies, 1977-2010. Minneapolis, MN: Research and Training Center on Community Living, Institute on Community Integration, University of Minnesota. 
Lorig, K. R., Sobel, D. S., Ritter, P. L., Laurent, D., \& Hobbs, M. (2001). Effect of a selfmanagement program on patients with chronic disease. Effective clinical practice: $E C P$, $4(6), 256-262$.

Magaña, S., Parish, S., Morales, M. A., Li, H., \& Fujiura, G. (2016). Racial and ethnic health disparities among people with intellectual and developmental disabilities. Intellectual and Developmental Disabilities, 54(3), 161-172.

Marks, B., Sisirak, J., \& Heller, T. (2010). Health Matters: The exercise and nutrition health education curriculum for people with developmental disabilities: ERIC.

Murphy-Berman, V. A., Berman, J. J., \& Campbell, E. (1998). Factors affecting health-care allocation decisions: A case of aversive racism? Journal of Applied Social Psychology, 28(24), 2239-2253. doi:10.1111/j.1559-1816.1998.tb01369.x

Nelson, A. R., Stith, A. Y., \& Smedley, B. D. (2002). Unequal treatment: Confronting racial and ethnic disparities in health care. Washington, DC: National Academies Press.

O'Leary, L., Cooper, S. A., \& Hughes-McCormack, L. (2017). Early death and causes of death of people with intellectual disabilities: A systematic review. Journal of Applied Research in Intellectual Disabilities.

Office of the United Nations High Commissioner for Human Rights, \& World Health Organization. (2008). The right to health: Fact sheet no. 31. Geneva: United Nations. Olmstead v. LC, No. No. 98-536, 527581 (Supreme Court 1999).

Ory, M. G., Ahn, S., Jiang, L., Lorig, K., Ritter, P., Laurent, D. D., . . Smith, M. L. (2013). National study of chronic disease self-management: Six-month outcome findings. Journal of Aging and Health, 25(7), 1258-1274. 
Ory, M. G., Ahn, S., Jiang, L., Smith, M. L., Ritter, P. L., Whitelaw, N., \& Lorig, K. (2013). Successes of a national study of the chronic disease self-management program: Meeting the triple aim of health care reform. Medical care, 51(11), 992-998.

Ouellette-Kuntz, H. (2005). Understanding health disparities and inequities faced by individuals with intellectual disabilities. Journal of Applied Research in Intellectual Disabilities, $18(2), 113-121$.

Panagioti, M., Richardson, G., Small, N., Murray, E., Rogers, A., Kennedy, A., . . Bower, P. (2014). Self-management support interventions to reduce health care utilisation without compromising outcomes: A systematic review and meta-analysis. BMC health services research, 14(1), 356.

Paradise, J. (2015). Medicaid moving forward. Retrieved from https://www.kff.org/healthreform/issue-brief/medicaid-moving-forward/

Perske, R. (1972). The dignity of risk. In W. Wolfensberger, B. Nirje, S. Olshansky, R. Perske, \& P. Roos (Eds.), The principle of normalization in human services (pp. 194-200). Toronto: National Institute on Mental Retardation.

Rimmer, J. H., \& Yamaki, K. (2006). Obesity and intellectual disability. Developmental Disabilities Research Reviews, 12(1), 22-27. doi:10.1002/mrdd.20091

Salzman, L. (2011). Guardianship for persons with mental illness: A legal and appropriate alternative? Saint Louis University Journal of Health Law \& Policy, 4, 279-330.

Spagnuolo, N. (2016). Building back wards in a 'post' institutional era: Hospital confinement, group home eviction, and Ontario's treatment of people labelled with intellectual disabilities. Disability Studies Quarterly, 36(4). doi:10.18061/dsq.v36i4.5279 
Swaine, J. G., Parish, S. L., Igdalsky, L., \& Powell, R. M. (2016). Consumers' and workers' perspectives about consumer-directed services in the United States. Disability and health journal, 9(3), 464-471.

Taggart, L., \& Cousins, W. (2014). Health promotion for people with intellectual and developmental disabilities. London: McGraw-Hill Education (UK).

The Council on Quality and Leadership. (2015). Basic assurances®: What really matters - a strong foundation for success enhancing health, safety and human security (3rd ed.). Towson, MD: Author.

The Council on Quality and Leadership. (2017a). Personal Outcome Measures: Measuring personal quality of life (3rd ed.). Towson, MD: Author.

The Council on Quality and Leadership. (2017b). The Personal Outcome Measures ${ }^{\circledR} 2017$ : Measuring outcomes now and into the future. Towson, MD: The Council on Quality and Leadership.

Timberlake, M. T., Leutz, W. N., Warfield, M. E., \& Chiri, G. (2014). "In the driver's seat": Parent perceptions of choice in a participant-directed medicaid waiver program for young children with autism. Journal of Autism and Developmental Disorders, 44(4), 903-914. doi:10.1007/s10803-013-1942-4

UN General Assembly. (1948). Universal declaration of human rights (217 [III] A). Paris: Author.

Wegman, M. P., Herndon, J. B., Muller, K. E., Graham, G. N., Vogel, W. B., Case, K. H., .. . Shenkman, E. A. (2015). Quality of care for chronic conditions among disabled medicaid enrollees: An evaluation of a 1915 (b) and (c) waiver program. Medical care, 53(7), 599606. doi:10.1097/MLR.0000000000000371 
Williamson, H. J., Perkins, E. A., Levin, B. L., Baldwin, J. A., Lulinski, A., Armstrong, M. I., \& Massey, O. T. (2017). Implementation of Medicaid managed long-term services and supports for adults with intellectual and/or developmental disabilities in Kansas. Intellectual and Developmental Disabilities, 55(2), 84-96.

World Health Organization. (2001). Healthy ageing - adults with intellectual disabilities: Summative report. Journal of Applied Research in Intellectual Disabilities, 14(3), 256275. doi:10.1046/j.1468-3148.2001.00071.x

Yamaki, K. (2005). Body weight status among adults with intellectual disability in the community. Mental Retardation, 43(1), 1-10. doi:10.1352/00476765(2005)43<1:BWSAAW>2.0.CO;2 
Table 1

Demographics of Sample $(n=1,341)$

\begin{tabular}{lcc}
\hline Characteristic & $n$ & $\%$ \\
\hline Age range & & \\
\hline 18 to 24 & 95 & $7.1 \%$ \\
\hline 25 to 34 & 250 & $18.6 \%$ \\
\hline 35 to 44 & 223 & $16.6 \%$ \\
\hline 45 to 54 & 279 & $20.8 \%$ \\
\hline 55 to 64 & 252 & $18.8 \%$ \\
\hline 65 to 74 & 122 & $9.1 \%$ \\
\hline $75+$ & 39 & $2.9 \%$ \\
\hline Gender & & \\
\hline Man & 719 & $53.6 \%$ \\
\hline Woman & 613 & $45.7 \%$ \\
\hline Race & & \\
\hline White & 998 & $74.4 \%$ \\
\hline Black or African American & 246 & $18.3 \%$ \\
\hline American Indian or Alaska Native & 54 & $4.0 \%$ \\
\hline Hispanic, Latinx, or Spanish Origin & 29 & $2.2 \%$ \\
\hline Other (Asian, Native Hawaiian, other & 16 & $1.2 \%$ \\
Pacific Islander, or other) & &
\end{tabular}

Primary method of communication

\begin{tabular}{lcc} 
Verbal/spoken language & 1102 & $82.2 \%$ \\
\hline Face/body expression & 169 & $12.6 \%$ \\
\hline Sign language & 16 & $1.2 \%$ \\
\hline Communication device & 14 & $1.0 \%$ \\
\hline Other & 33 & $2.5 \%$
\end{tabular}

Guardianship status

Independent decision making $\quad 370 \quad 27.6 \%$

Assisted decision making (supported and $\quad 494 \quad 36.8 \%$ limited guardianship)

$494-36.8 \%$

$\begin{array}{lcc}\text { Full/plenary guardianship } & 423 & 31.5 \% \\ \text { Other } & 35 & 2.6 \%\end{array}$

\begin{tabular}{lcc} 
Residence type & & \\
\hline Own home/apartment & 284 & $21.2 \%$ \\
\hline Family's house & 213 & $15.9 \%$ \\
\hline Host family/family foster care & 24 & $1.8 \%$ \\
\hline Provider-operated house or apartment & 677 & $50.5 \%$ \\
\hline Private ICFDD & 22 & $1.6 \%$ \\
\hline
\end{tabular}




\begin{tabular}{lcc}
\hline State operated HCBS group home & 43 & $3.2 \%$ \\
\hline State operated ICFDD & 25 & $1.9 \%$ \\
\hline Other & 22 & $1.6 \%$ \\
\hline Average daily support & & \\
\hline On call - support as needed & 28 & $2.1 \%$ \\
\hline 0 to 3 hours/day & 60 & $4.5 \%$ \\
\hline 3.1 to 6 hours/day & 94 & $7.0 \%$ \\
\hline 6.1 to 12 hours/day & 155 & $11.6 \%$ \\
\hline 12.1 to 23 hours/day & 76 & $5.7 \%$ \\
\hline $24 / 7$ - around the clock & 819 & $61.1 \%$ \\
\hline Other & 46 & $3.4 \%$ \\
\hline $\begin{array}{l}\text { Receives services from a managed care } \\
\text { organization }\end{array}$ & 397 & $33.2 \%$ \\
\hline Complex medical support needs & 159 & $11.9 \%$ \\
\hline Comprehensive behavioral support needs & 270 & $20.1 \%$ \\
\hline
\end{tabular}

Note. ICFDD = Intermediate care facility for people with developmental disabilities. HCBS = Home and Community Based Services. 
Table 2

Descriptive Statistics

\begin{tabular}{lcc}
\hline Variable & $n$ & $\%$ \\
\hline Person is supported to self-manage their personal health & 663 & $55.2 \%$ \\
\hline Participant sees health care professionals & 1228 & $99.1 \%$ \\
\hline Participant has a primary care doctor & 1228 & $99.8 \%$ \\
\hline $\begin{array}{l}\text { Health care profs. identified the person's best possible health situation, } \\
\text { addressing any health care issues or concerns, and interventions }\end{array}$ & 1154 & $94.8 \%$ \\
\hline $\begin{array}{l}\text { Health intervention services have been selected by the person in } \\
\text { consultation with health care professional }\end{array}$ & 889 & $73.2 \%$ \\
\hline $\begin{array}{l}\text { Health intervention services, as desired by the person, have been effective } \\
\text { If the person needs devices or equipment such as glasses, hearing aids, or } \\
\text { dentures, these are available and in good repair }\end{array}$ & 1027 & $84.6 \%$ \\
\hline $\begin{array}{l}\text { Best possible health - outcome present } \\
\text { Organization knows person's definition of best possible health }\end{array}$ & 841 & $94.0 \%$ \\
\hline $\begin{array}{l}\text { Supports provided for the person to promote and maintain best possible } \\
\text { health if needed/requested }\end{array}$ & 1059 & $71.0 \%$ \\
\hline $\begin{array}{l}\text { Organization assures that the person has support to obtain regular medical } \\
\text { and health services }\end{array}$ & 1147 & $95.0 \%$ \\
\hline $\begin{array}{l}\text { Organization responds to the person's changing health needs and } \\
\text { preferences }\end{array}$ & $91.3 \%$ \\
$\begin{array}{l}\text { Organization supports person to be aware of their medical issues and their } \\
\text { impact }\end{array}$ & 975 & $80.6 \%$ \\
\hline
\end{tabular}


Table 3

Who is Supported to Self-Manage their Health?

\begin{tabular}{|c|c|c|c|}
\hline Model & O.R. & \multicolumn{2}{|c|}{$95 \%$ C.I. } \\
\hline \multicolumn{4}{|l|}{ Age range (ref: 18 to 24 ) } \\
\hline 25 to 34 & 1.33 & 0.70 & 2.52 \\
\hline 35 to 44 & 1.40 & 0.72 & 2.72 \\
\hline 45 to 54 & 1.34 & 0.70 & 2.57 \\
\hline 55 to 64 & 1.47 & 0.76 & 2.85 \\
\hline 65 to 74 & $2.90 * *$ & 1.36 & 6.21 \\
\hline $75+$ & $3.47 *$ & 1.26 & 9.52 \\
\hline Woman (ref: Man) & 1.17 & 0.88 & 1.57 \\
\hline \multicolumn{4}{|l|}{ Race/ethnicity (ref: White) } \\
\hline Black or African American & $0.64 *$ & 0.44 & 0.94 \\
\hline Hispanic or Latinx & 1.37 & 0.53 & 3.57 \\
\hline American Indian or Indigenous Alaskan & $2.64 *$ & 1.13 & 6.16 \\
\hline $\begin{array}{l}\text { Other (including Asian, other Pacific } \\
\text { Islander, Native Hawaiian) }\end{array}$ & $0.08 *$ & 0.01 & 0.75 \\
\hline \multicolumn{4}{|l|}{ Primary communication method (ref: verbal) } \\
\hline Sign language & 0.45 & 0.09 & 2.19 \\
\hline Communication device & 0.86 & 0.18 & 3.99 \\
\hline Body expression & 0.91 & 0.58 & 1.44 \\
\hline Other & 0.86 & 0.37 & 1.99 \\
\hline \multicolumn{4}{|l|}{ Disability } \\
\hline Autism spectrum disorder & 1.07 & 0.65 & 1.77 \\
\hline Brain injury & 1.01 & 0.29 & 3.45 \\
\hline Cerebral Palsy & 0.86 & 0.56 & 1.32 \\
\hline Down Syndrome & 1.22 & 0.66 & 2.26 \\
\hline Seizure disorder/neurological problems & 0.94 & 0.67 & 1.34 \\
\hline Anxiety disorder & 1.24 & 0.81 & 1.89 \\
\hline Behavior challenges & $1.64 *$ & 1.04 & 2.59 \\
\hline Impulse-control disorder & 1.46 & 0.80 & 2.64 \\
\hline Mood disorder & 0.72 & 0.49 & 1.07 \\
\hline Personality/psychotic disorder & $0.56^{*}$ & 0.35 & 0.90 \\
\hline Other mental illness/psychiatric disability & 0.84 & 0.53 & 1.32 \\
\hline Hearing loss - severe or profound & 1.36 & 0.69 & 2.68 \\
\hline Legally blind & 1.88 & 0.87 & 4.10 \\
\hline Physical disability & 0.87 & 0.49 & 1.54 \\
\hline \multicolumn{4}{|l|}{ Guardianship (ref: independent decision making) } \\
\hline Assisted decision making & $0.28 * * *$ & 0.19 & 0.41 \\
\hline
\end{tabular}


$\begin{array}{lccc}\text { Full plenary guardianship } & 0.57 * * & 0.38 & 0.86 \\ \text { Other } & 0.49 & 0.20 & 1.17\end{array}$

Residence type (ref: Own home/apartment)

$\begin{array}{llll}\text { Family's house } & 0.53 * & 0.30 & 0.94\end{array}$

$\begin{array}{llll}\text { Host family/family foster care } & 0.57 & 0.18 & 1.77\end{array}$

$\begin{array}{llll}\text { Provider-operated house or apartment } & 1.22 & 0.82 & 1.82\end{array}$

$\begin{array}{llll}\text { Private ICFDD } & 0.50 & 0.15 & 1.62\end{array}$

$\begin{array}{llll}\text { State operated HCBS group home } & 1.58 & 0.68 & 3.70\end{array}$

$\begin{array}{llll}\text { State operated ICFDD } & 2.20 & 0.74 & 6.56\end{array}$

$\begin{array}{llll}\text { Other } & 0.77 & 0.25 & 2.34\end{array}$

Daily support (ref: as needed - on call)

\begin{tabular}{lccc}
\hline 0 to 3 hours/day & 1.75 & 0.43 & 7.04 \\
\hline 3.1 to 6 hours/day & 0.67 & 0.19 & 2.33 \\
\hline 6.1 to 12 hours/day & 0.74 & 0.22 & 2.50 \\
\hline 12.1 to 23 hours/day & 0.77 & 0.21 & 2.84 \\
\hline 24/7 - around the clock & $0.25^{*}$ & 0.08 & 0.84 \\
\hline Other & 0.60 & 0.16 & 2.32 \\
\hline Complex medical needs & $1.78^{*}$ & 1.10 & 2.87 \\
\hline Comprehensive behavioral health needs & 1.15 & 0.76 & 1.75 \\
\hline $\begin{array}{l}\text { Receives services from a managed care } \\
\text { organization }\end{array}$ & $0.52^{* * *}$ & 0.38 & 0.72 \\
\hline
\end{tabular}

Note. $* \mathrm{p}<.05, * * \mathrm{p}<.01, * * * \mathrm{p}<.001$. O.R. $=$ Odds ratio. C.I. $=$ Confidence interval. ICFDD $=$ Intermediate care facility for people with developmental disabilities. HCBS = Home and community based services. $\mathrm{DSP}=$ direct support professionals. 
Table 4

Impact of Self-Management on Health and Supports

\begin{tabular}{|c|c|c|c|c|c|c|c|}
\hline \multirow[b]{2}{*}{ Model } & \multicolumn{7}{|c|}{ Nagelkerke } \\
\hline & $-2 L L$ & $d f$ & $\chi^{2}$ & $R^{2}$ & O.R. & \multicolumn{2}{|c|}{ 95\% C.I. } \\
\hline \multicolumn{8}{|l|}{ Health outcomes } \\
\hline $\begin{array}{l}\text { Sees health care } \\
\text { professionals }\end{array}$ & 117.74 & 7 & 6.71 & 0.06 & 1.34 & 0.38 & 4.71 \\
\hline Has primary care doctor & 32.74 & 7 & 8.99 & 0.22 & 0.00 & 0.00 & 0.00 \\
\hline $\begin{array}{l}\text { Devices or equipment } \\
\text { available and in good repair (if } \\
\text { applicable) }\end{array}$ & 385.19 & 7 & 10.81 & 0.03 & 1.54 & 0.92 & 2.92 \\
\hline $\begin{array}{l}\text { Health care professionals } \\
\text { identified best possible } \\
\text { health situation, including } \\
\text { addressing any health care } \\
\text { issues or concerns and } \\
\text { interventions*** }\end{array}$ & 450.64 & 7 & 26.11 & 0.07 & $2.81 * * *$ & 1.60 & 4.96 \\
\hline $\begin{array}{l}\text { Health intervention services } \\
\text { selected by the person in } \\
\text { consultation with health } \\
\text { care professional*** }\end{array}$ & 1126.94 & 7 & 219.55 & 0.25 & $7.37 * * *$ & 5.39 & 10.07 \\
\hline $\begin{array}{l}\text { Health intervention services } \\
\text { have been effective*** }\end{array}$ & 944.68 & 7 & 52.51 & 0.08 & $2.30 * * *$ & 1.64 & 3.24 \\
\hline \multicolumn{8}{|l|}{ Organizational supports } \\
\hline $\begin{array}{l}\text { Organization knows } \\
\text { person's definition of best } \\
\text { possible health*** }\end{array}$ & 789.93 & 7 & 121.75 & 0.18 & $9.03 * * *$ & 5.65 & 14.41 \\
\hline $\begin{array}{l}\text { Supports provided to } \\
\text { promote and maintain best } \\
\text { possible health*** }\end{array}$ & 655.41 & 7 & 47.91 & 0.09 & $4.10 * * *$ & 2.57 & 6.54 \\
\hline $\begin{array}{l}\text { Organization supports person } \\
\text { to obtain regular medical and } \\
\text { health services } * * *\end{array}$ & 408.9 & 7 & 68.41 & 0.17 & $5.12 * * *$ & 2.75 & 9.55 \\
\hline $\begin{array}{l}\text { Organization responds to } \\
\text { the person's changing health } \\
\text { needs and preferences } * * *\end{array}$ & 496.1 & 7 & 54.26 & 0.12 & $6.23 * * *$ & 3.34 & 11.48 \\
\hline $\begin{array}{l}\text { Organization supports person } \\
\text { to be aware of their medical } \\
\text { issues and their impact*** }\end{array}$ & 876.34 & 7 & 281.37 & 0.34 & $22.42 * * *$ & 16.69 & 36.72 \\
\hline
\end{tabular}

